\title{
Remote sensing monitoring of grassland vegetation growth in the Beijing-Tianjin sandstorm source project area from 2000 to 2010
}

\author{
Xiuchun Yang a,b, Bin Xua ${ }^{a}$, Yunxiang Jin a ${ }^{a}$ Zhihao Qin ${ }^{a}$, Hailong Ma ${ }^{a}$, Jinya $\mathrm{Li}^{\mathrm{a}}$, \\ Fen Zhao ${ }^{\mathrm{a}}$, Shi Chen ${ }^{\mathrm{c}}$, Xiaohua Zhu ${ }^{\mathrm{d}, *}$ \\ a Key Laboratory of Agri-informatics, Ministry of Agriculture/Institute of Agricultural Resources and Regional Planning, \\ Chinese Academy of Agricultural Sciences, Beijing 100081, China \\ ${ }^{\mathrm{b}}$ College of Environment and Planning, Shangqiu Normal University, Henan 476000, China \\ c Collegeof Territorial Resources and Tourism, Anhui Normal University, Wuhu 241000, China \\ ${ }^{\mathrm{d}}$ Institute of Geographic Sciences and Natural Resources Research, Chinese Academy of Sciences, Beijing 100101, China
}

\section{A R T I C L E I N F O}

\section{Article history:}

Received 17 December 2013

Received in revised form 1 April 2014

Accepted 28 April 2014

\section{Keywords:}

Grassland vegetation growth

Remote sensing

Beijing-Tianjin sandstorm source control

project

Project effect

Agro-ecosystems

\begin{abstract}
A B S T R A C T
Grassland is not only an important landscape of the Beijing-Tianjin sandstorm source control project area, but also a significant object of the Beijing-Tianjin sandstorm source control project. By taking the situation in 2000 as the base of comparison and using the established grassland vegetation growth model, the monitoring and evaluation of grassland vegetation dynamic variation in the project area from 2000 to 2010 was conducted based on MODIS 16 days NDVI data. The conclusions are as follows: (1) The comparative result of average growth between each year from 2001 to 2010 and the base year was on the good side in general; the grassland growth was good both in the early and later periods of grassland growth peak season than in the first years of the project implementation, indicating that the implementation of the Beijing-Tianjin sandstorm source project has significantly improved the growth conditions of grassland vegetation; (2) With regard to the annual dynamic variation of grassland growth, the area proportions of the grasslands, of which the average grassland growth was on the good side, fluctuated and increased slightly with the time changes in general. The area proportions of the grasslands, of which the average grassland growth was on the bad side, fluctuated and decreased in general. The area proportions of the grasslands with normal growth showed an increasing overall trend; (3) From the regional perceptive on four zones, including the northern arid grassland desertification control zone, Hunshandake sandy land control zone, the farming-pastoral area of desertified land control zone, and the water conservation zone of Yanshan hills and mountains, except that the grassland growth in the farmingpastoral area of desertified land control zone was bad, the average growth of other three zones was good each year from 2001 to 2010 compared with the base year. (4) In respect of space, the regions with big grassland growth variation in the project area were concentrated in the western and eastern sections of the northern arid grassland desertification control zone and the western section of Hunshandake sandy land control zone. The grassland growth variation in the water conservation zone of Yanshan hills and mountains and the farming-pastoral area of desertified land control zone were relatively stable. On one hand, the conclusions of this paper can evaluate the effectiveness of the project control, on the other hand, it can also provide scientific basics to grassland management departments, facilitate the rational utilization of grassland, and preserve the regional ecological balance.
\end{abstract}

(C) 2014 Elsevier Ltd. All rights reserved.

\section{Introduction}

China's northern area has frequently suffered from sandstorms since the 1990s. Especially in the spring of 2000, sandstorms

\footnotetext{
* Corresponding author. Tel.: +86 1064889584 .

E-mail address: zhuxh@igsnrr.ac.cn (X.Zhu).
}

just occurred 12 times in North China, it was three times more than those happened in the 1990s, and made North China suffer social, economic and other multiple effects and losses. In order to improve and optimize the ecological and environmental conditions of Beijing, Tianjin and surrounding areas, protect and build forest and grass vegetation, restrain desertification expansion and control land, the Chinese government has timely made a project decision to control the ecological degradation and conduct 
construction of ecological circle around Beijing and Tianjin. The project started a pilot in June 2000 and achieved initial success. With the approval by the State Council, the former State Planning Commission, Ministry of Finance, State Forestry Administration, Ministry of Agriculture and Ministry of Water Resources jointly issued the "Beijing-Tianjin sandstorm source control project plan (2001-2010)" in March 2002, and at this point, the Beijing-Tianjin sandstorm source control project was in full swing. The Beijing-Tianjin sandstorm source control project is a landmark project in the field of nationalwide ecological protection and construction. The grassland is an important landscape of the Beijing-Tianjin sandstorm source project area, as well as a significant object of the control. Thus, as the first stage of Beijing-Tianjin sandstorm source control project had been completed in 2010, to conduct a benefit evaluation of the grassland project is not only conducive to objectively evaluate the effectiveness of the entire first phase of the grassland construction project, but also affect the overall ecological benefits in the project area, especially very important to guide the planning of the second stage project and work better in the future (Gonzalo et al., 2010).

Growth remote sensing monitoring of grassland vegetation directly reflects the herbage growth status, it is an important part of ecological status evaluation and can timely provide guidance to agricultural management and production. The growth remote sensing monitoring originated in the 1980s, the USA, Canada, the former Soviet Union and other countries of the EU have done numerous researches and monitoring studies on the indicators and methodologies of crop growth remote sensing monitoring (Beatriz et al., 2009; Ma et al., 2008; Lobell et al., 2003; Adel et al., 2007). After defining the concept of crop growth, the growth monitoring of vegetation entered into the stage of indicator development and quantitative monitoring (John et al., 2013). After 1999, the growth monitoring mainly used the Moderate-resolution Imaging Spectroradiometer (MODIS) data (Pieter et al., 2006; Mao et al., 2012; Zhou et al., 2001; Barbosa et al., 2006; Lobell et al., 2003); Wu et al. (2000) used maximum NDVI image in every 10 days compared with the previous year in the same period to achieve the nationwide crop growth remote sensing monitoring; some researchers discussed the monitoring indicators and reference standards of crop growth, and developed 10-day and monthly MODIS/NDVI comparative models and MODIS/NDVI semi-quantitative monitoring indicator model (Guo et al., 2012; Ma et al., 2008). The crop growth monitoring has a long history, and the monitoring theories and methods are relatively mature, so the growth remote sensing monitoring of grassland vegetation borrowed a part of ideas from the crop remote sensing monitoring methods. The grassland growth monitoring methods currently include direct monitoring method, vegetation growth process monitoring method, contemporaneous comparative method (Wu et al., 2010) and anomaly growth monitoring method (Xu et al., 2013). Tashi (2004) used the NOAA/AVHRR data and ground monitoring data to establish the model of vegetation index and herbage growth, meteorological and elements herbage growth monitoring, and initially developed the level values of herbage growth. Wu et al. (2010) used the morphological characteristics of vegetation index curve to monitor current status of vegetation growth and the vegetation growth trend. The vegetation growth process monitoring is extensively used in the grassland vegetation growth monitoring. The contemporaneous comparative method frequently uses the NDVI for monitoring. Based on the contemporaneous comparative method, Xu et al. (2013) made its improvements in 2013 and put forward the anomaly growth monitoring method, and used the MODIS/NDVI data to adopt the anomaly growth index model and conducted the growth monitoring of grassland vegetation in China in 2008. Among these monitoring methods, the contemporaneous comparative method has simple calculation and is extensively used in practical researches and applications, but this calculation method does not eliminate the shortcomings of vegetation indices. The anomaly growth monitoring method adopted a normalized method to improve the existing shortages of vegetation indices and thus obtained more accurate monitoring results.

In this study, the grasslands of Beijing-Tianjin sandstorm source project area has been taken as the research object, and the grassland vegetation growth index model has been established based on the anomaly growth monitoring method, and carried out the remote sensing monitoring of grassland vegetation growth status in the project area within a period of eleven years from 2000 to 2010, and performed the project results evaluation. The achievements of this paper have important reference value to promote regional economic development, improve ecological status and conduct scientific management and rational utilization of grasslands (Harini et al., 2013).

\section{Methods}

\subsection{Study area}

The Beijing-Tianjin sandstorm source project area (Fig. 1) ranges from Darhan Muming'an united banner of Inner Mongolia in the west to Ar Horqin banner of Inner Mongolia in the east and from Dai County of Shanxi province in the south to East Ujimqin banner of Inner Mongolia in the north. It spans a horizontal distance of nearly $700 \mathrm{~km}$ from east to west and a vertical distance of nearly $600 \mathrm{~km}$ from south to north, covering 75 counties in five provinces (autonomous regions and municipalities) of Beijing, Tianjin, Hebei, Shanxi and Inner Mongolia, including six counties in Beijing, one in Tianjin, 24 in Hebei, 13 in Shanxi and 31 in Inner Mongolia, covering a total land area of $458,000 \mathrm{~km}^{2}$, of which $101,800 \mathrm{~km}^{2}$ are desertified land area. The Beijing-Tianjin sandstorm source project area covers a large area and have different bioclimatic zones and soil types. Therefore, the project area is divided into four zones in accordance with arrangement, climate, vegetation, soil and terrain and landscapes of Beijing-Tianjin sandstorm source control project, namely, the northern arid grassland desertification control zone, the Hunshandake sandy land control zone, the farming-pastoral area of desertified land control zone and the water conservation zone of Yanshan hills and mountains.

The Beijing-Tianjin sandstorm source project area consists of plain, mountainous and highland regions. It has suffered from severe desertification as Hunshandake sandy land and Horqin sandy land are distributed in the area, which restrict agricultural management and production in the region. There are two climate belts and five climate zones in the project area, including warm temperate semi-humid zone, temperate semi-humid zone, temperate semi-arid zone, temperate arid zone and temperate extreme arid zone from south to north and east to west. The climate is arid, cold, and windy. A wind is the natural characteristic of desertified regions that plays an important role in the expansion of desertification and the shaping of desertified landform. Strong wind mainly occurs in winter and spring, in which there are the fewest amount of precipitation. Meanwhile, there are the fewest ground surface vegetations in winter and spring, so the arid sandy ground surface could be easily eroded by strong wind and lead to desertification.

The project area's total land area is $45.80 \times 10^{4} \mathrm{~km}^{2}$, of which grassland has the largest range of about $26.63 \times 10^{4} \mathrm{~km}^{2}$, accounting for $58.1 \%$ of the total area. The grassland is the biggest ecological system in the project area, mainly including 12 grassland types (Fig. 1), namely Low-land meadow, Warm tussock, Warm shrubby tussock, Tropical tussock, Montane meadow, Apline meadow, Temperate meadow steppe, Temperate steppe desert, Temperate steppe, Temperate desert steppe, Temperate desert, and Marsh. The 


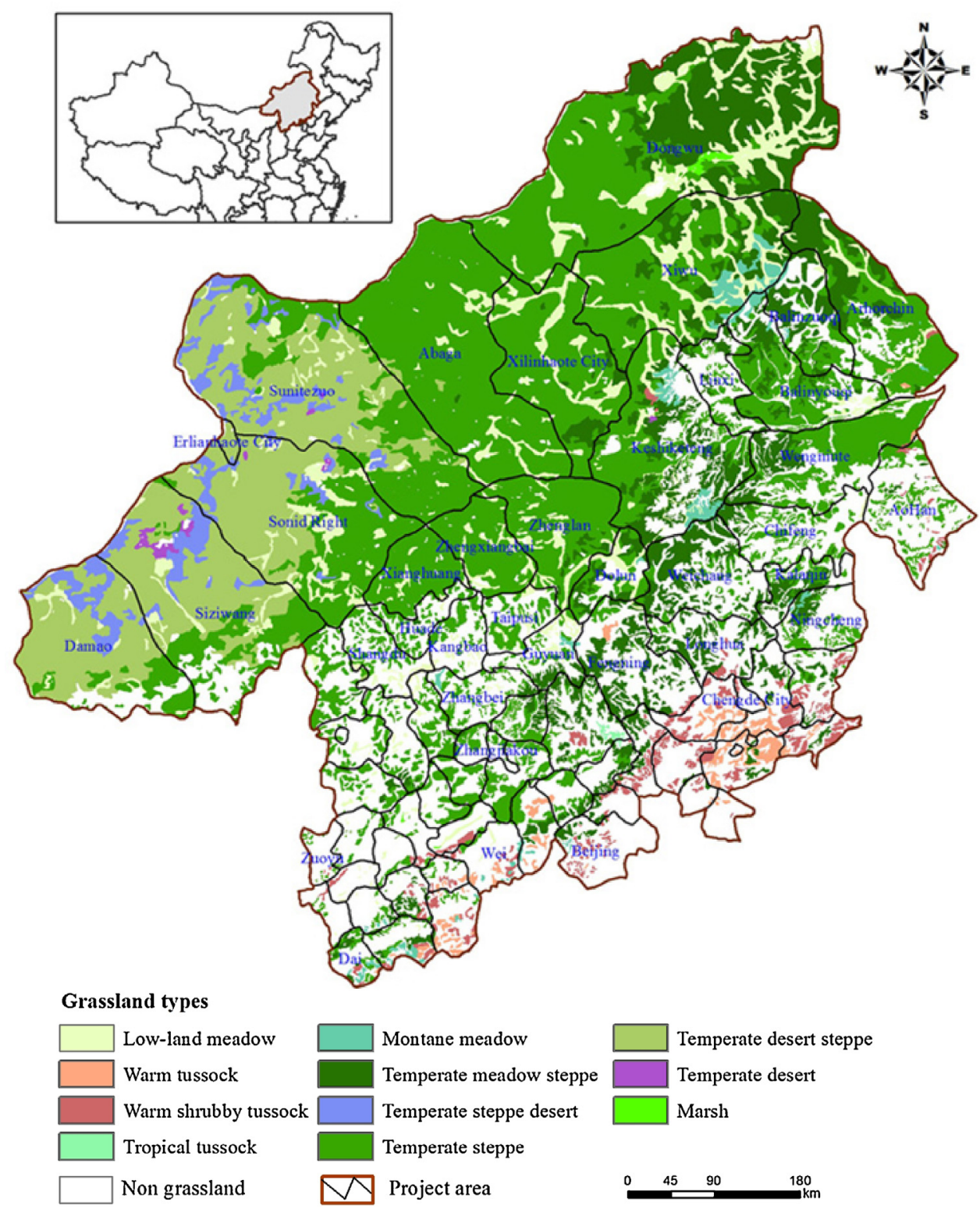

Fig. 1. The scope of sandstorm source project area of Beijing and Tianjin and distribution of grassland types.

temperate steppe is the biggest grassland type in the project area, accounting for $49.54 \%$ of the total grassland area. The temperate meadow steppe comes next, accounting for $17.13 \%$. The third is temperate desert steppe, accounting for $15.63 \%$. The fourth is lowland meadow, accounting for $9.89 \%$. The apline meadow has the minimum grassland area, accounting for $0.01 \%$.

\subsection{Methods}

\subsubsection{Data sources}

The grassland vegetation growth is controlled by local climate factors (Pielke et al., 1998; Wang et al., 2006; Yongyut et al., 2011; Li et al., 2012). The Beijing-Tianjin sandstorm source control project area lies in temperate arid and semi-arid regions in the north of China. The growing season of grassland vegetation is mainly from May to September of each year; the peak season is in August; and the grassland vegetation enters in the withered yellow period after October. Therefore, the remote sensing data should be downloaded from May to September while the remote sensing technology is used in the growth status monitoring of grassland vegetation.

The remote sensing data could be obtained from MOD13 data products on the website of NASA (http://modis.gsfc.nasa.gov/), which belong to terrestrial level-2 standard data products, the content is rasterized vegetation index products. They are 16-day synthetic NDVI data with spatial resolution of $250 \mathrm{~m}$, the data format is HDF raster data and Sinusoidal projection. The NDVI data is processed by projection conversion with mosaic MRT software to obtain NDVI data of study zone from May to September of each year from 2000 to 2010. The Maximum Value Composite (MVC) can further eliminate the interference caused by the cloud, atmosphere and solar zenith angle (Holben, 1986). The MVC is used to synthesize the maximum NDVI of vegetation growing season from May to September, as well as the maximum NDVI of the early period (from July 28 to August 12) and the later period (from August 13 to August 28) of vegetation growth peak season. Moreover, the grassland vector data partition is conducted to obtain the NDVI of grassland distribution zones in the project area. 
Other data sources include grassland distribution vector data and administrative division data. The grassland distribution vector data are from digitized maps in the Atlas of Grassland Resources of China (1996) published by China Cartographic Publishing House. The administrative division data are from the database of National Geomatics Center of China, also functioned as National Archives for Surveying and Mapping.

\subsubsection{Methods}

The grassland vegetation growth is the overall growth status of grassland vegetation (Karin et al., 1997; Pettorelli et al., 2005; Li et al., 2011; Wittich et al., 2008), and usually compared with the status of previous grassland vegetation to illustrate the current growth situation of the grassland vegetation. Generally speaking, the grassland vegetation growth is a relative concept. Therefore, the growth remote sensing monitoring and evaluation of grassland vegetation (Liu et al., 2014; Jiang et al., 2014) usually compares the grassland vegetation indices in the monitoring period with those in the base period to determine the grassland growth in the monitoring period. In practical operating process, the base period is often used to determine historical average situations of the annual grassland vegetation monitoring in the past years and previous year. The comparisons between the growth in the monitoring year and historical average growth in the past years show results. The comparisons with that of previous year can explain how the growth status is in the monitoring year and previous year. The Beijing-Tianjin sandstorm source control project has come into effect since 2000 in order to objectively monitor and evaluate the grassland vegetation growth status in the project area (Benjamin et al., 2012), we will take the year 2000 as a base for comparison to monitor and evaluate the grassland vegetation dynamic changes of in the project area from 2000 to 2010.

The growth remote sensing monitoring methods of grassland vegetation are generally composed of three aspects, including the calculation and composition of vegetation indices, grassland growth determination and classification, and statistics and analysis of image data (Xu et al., 2013). The grassland vegetation growth index $(G I)$ is built by using the anomaly growth monitoring method, and the Eq. (1) calculates the growth index from the year 2001 to 2010 compared with the base year 2000. Then the classification is done according to the size growth index values.

$G I=\frac{N D V I_{m}-N D V I_{n}}{N D V I_{m}+N D V I_{n}}$

In the formula, GI means growth index, and $N D V I_{m}$ and $N D V I_{n}$ stand for vegetation indices in different periods.

In order to make a scientific and reasonable evaluation of grassland vegetation growth, the grassland vegetation growth of effectively monitored area was classified into five levels according to ground authentication data and test results of many years and based on the magnitude of the GI values, namely good, relatively good, normal, relatively poor, and poor. Values lower than -0.15 are considered to be poor, relatively poor is between -0.15 and -0.05 , normal is greater than -0.05 and less than 0.05 , relatively good is between 0.05 and 0.15 , and good is greater than 0.15 . Moreover, there will be remote sensing data quality issues, cloud interference and non-grassland part called non-monitored regions. The regional statistics could be conducted by GIS, on the basis, of growth spatial distribution diagram so as to obtain annual grassland growth statistics or those in the grassland growth peak season. Then, the summary statistics can be further calculated in pursuance to obtain grassland vegetation growth of monitored regions in different periods.
Table 1

The comparative growth conditions of grassland vegetation between the base year and each year from 2001 to 2010.

\begin{tabular}{lrrllr}
\hline \multirow{2}{*}{ Period } & \multicolumn{5}{l}{ Percentage of grassland area (\%) } \\
\cline { 2 - 6 } & \multicolumn{1}{c}{ Poor } & Relatively poor & Normal & Relatively good & Good \\
\hline 2001 & 13.07 & 32.89 & 37.42 & 14.67 & 1.95 \\
2002 & 6.73 & 24.81 & 40.41 & 21.90 & 6.15 \\
2003 & 2.41 & 9.70 & 32.55 & 36.89 & 18.45 \\
2004 & 1.08 & 13.45 & 54.67 & 28.06 & 2.73 \\
2005 & 8.36 & 23.49 & 39.89 & 23.04 & 5.22 \\
2006 & 4.02 & 28.71 & 47.69 & 17.77 & 1.81 \\
2007 & 6.32 & 24.92 & 41.96 & 22.04 & 4.76 \\
2008 & 0.95 & 11.20 & 45.24 & 33.07 & 9.53 \\
2009 & 5.95 & 26.71 & 45.24 & 19.26 & 2.84 \\
2010 & 4.17 & 14.65 & 34.10 & 31.34 & 15.74 \\
Average & 5.31 & 21.05 & 41.92 & 24.80 & 6.92 \\
\hline
\end{tabular}

\section{Results}

\subsection{Overall growth in the grassland growing season}

The comparative grassland growth results of Beijing-Tianjin sandstorm source project area between each year from 2001 to 2010 and the base year 2000 were obtained on the basis of calculation of grassland vegetation growth from May to September (Table 1). The comparative average growth results between each year from 2001 to 2010 and the year 2000 were on the good side in general. The areas of the grasslands with good, relatively good, normal, relatively poor and poor growth respectively accounted for $6.92 \%, 24.80 \%, 41.92 \%, 21.05 \%$ and $5.31 \%$ of the total grassland area in the project area. The area of grasslands, of which the growth was on the good side (the term "on the good side" means "relatively good and good"), accounted for $31.72 \%$ of the monitoring grassland area in the project area. That of grasslands, of which the growth was on the poor side (the term "on the poor side" means "relatively poor" and "poor"), accounted for $26.36 \%$, indicating that the grassland growth in the project area was better than that in 2000 .

\subsection{Annual dynamic variation of growth in the grassland growing season}

With regard to the annual dynamic variation of grassland growth (Fig. 2), the average growth of grassland vegetation in the project area from May to September of each year from 2001 to 2010 was better than that in the base year. The area proportion of the grasslands, of which the average growth was on the good side, fluctuated and increased slightly with the time changes in general,

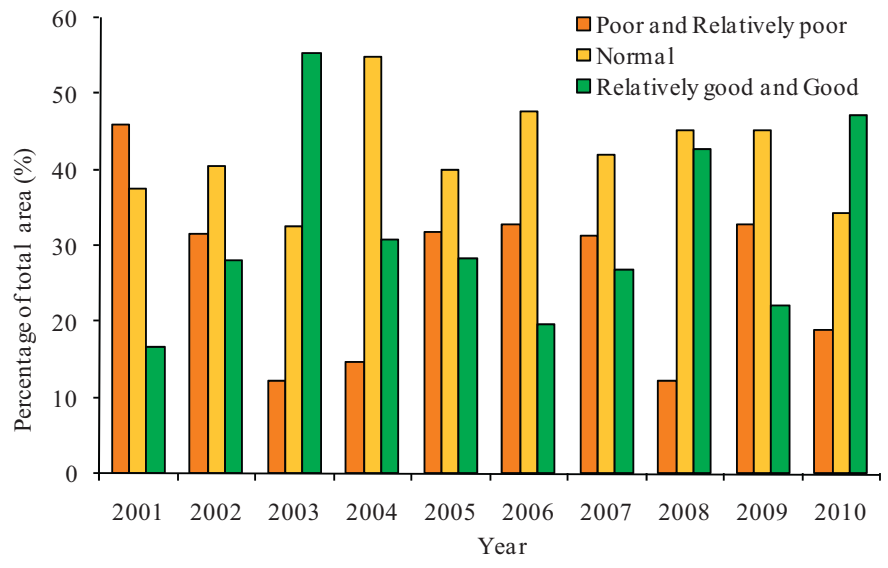

Fig. 2. Dynamic variation of comparative grassland vegetation average growth between the year 2000 and each year from 2001 to 2010 . 


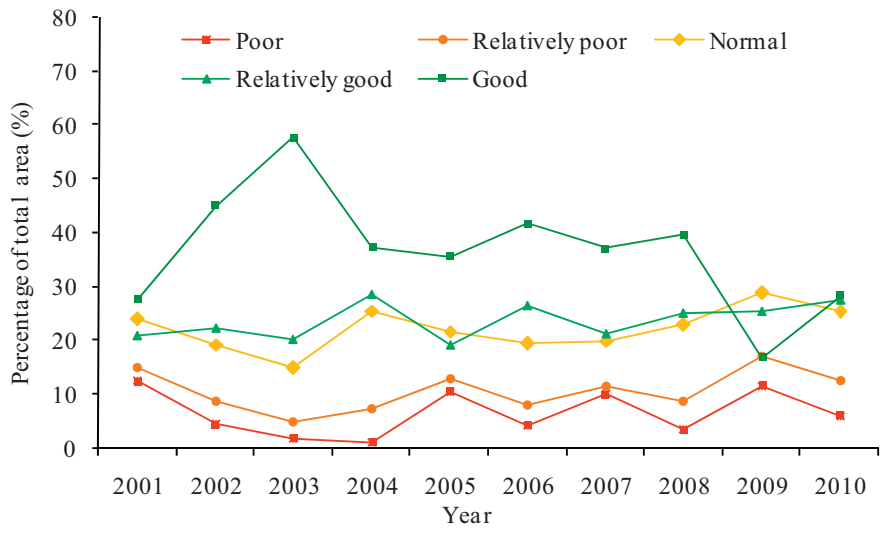

Fig. 3. Comparative growth trends in the prior period of grassland growth peak season between the base year and each year from 2001 to 2010. Region 1: Northern arid grassland desertification control zone; Region 2: Hunshandake sandy land control zone; Region 3: Water conservation zone of Yanshan hills and mountains; Region 4: Farming-pastoral area of desertified land control zone.

reaching the maximum value of $55.34 \%$ in 2003 ; The area proportion of the grasslands, of which the growth was on the good side, was $16.62 \%$ in 2001 , reaching the minimum value. The area proportion of the grasslands, of which the average growth was on the bad side, fluctuated and decreased in general, reaching the minimum value of $12.11 \%$ in 2003 , the second lowest value of $12.15 \%$ in 2008 , and the maximum value of $45.96 \%$ in 2001 . The area proportion of the grasslands, of which the average growth was normal, showed an increasing overall trend, reaching the maximum value $54.67 \%$ in 2004, and the minimum value 32.55\% in 2003 .

The growth comparison was conducted between the base year and each year from 2001 to 2010 . The grassland growth in 2001 and 2002 was worse than that in 2000 and the grassland area proportions were $45.96 \%$ and $31.54 \%$, respectively; the grassland growth in 2003 and 2004 was better than that in 2000 and the grassland area proportions were $55.34 \%$ and $30.79 \%$, respectively. The area proportion reached the maximum value in 2003 . The grassland growth from 2005 to 2007 was worse than that in 2000 and the grassland area proportions were $31.84 \%, 32.73 \%$ and $31.24 \%$, respectively. The grassland growth in 2008 was worse than that in 2000 and the grassland area proportion was $42.61 \%$. The grassland growth was on the poor side in general since the Inner Mongolia suffered from aridity in 2009 , and the grassland area proportion was $32.66 \%$. The grassland growth in 2010 was on the good side and the grassland area proportions was $47.08 \%$.

\subsection{Growth variation in the previous period and later period of the grassland growth peak season}

The overall grassland growth in the project area in the previous period of grassland growth peak season from 2001 to 2010 was far better than that in the base year (Fig. 3). During the monitoring period, the grassland area, of which the growth was good, relatively good, normal, relatively poor and poor, respectively accounted for $36.70 \%, 23.72 \%, 22.24 \%, 10.72 \%$ and $6.61 \%$ of the total grassland area in the project area. The area of grasslands, of which the growth was on the good side, was $60.43 \%$; while that of grasslands, of which the growth was on the poor side, was $17.33 \%$. That of the grasslands, of which the growth was on the good side, was more than that of the grasslands, of which the growth was on the poor side. The area proportion of grasslands, of which the growth was on the good side, fluctuated and decreased in general, reaching the minimum value of $42.26 \%$ in 2009 , and the maximum value of $78.03 \%$ in 2003 . The area proportion of grasslands, of which the growth was on the poor
Table 2

Comparative growth trends in the later period of grassland growth peak season between the base year and each year from 2001 to 2010 .

\begin{tabular}{lrrllr}
\hline \multirow{2}{*}{ Period } & \multicolumn{5}{l}{ Percentage of grassland area (\%) } \\
\cline { 2 - 6 } & \multicolumn{1}{c}{ Poor } & Relatively poor & Normal & Relatively good & Good \\
\hline 2001 & 22.85 & 19.03 & 30.19 & 17.86 & 10.08 \\
2002 & 13.20 & 20.36 & 28.46 & 20.47 & 17.51 \\
2003 & 7.76 & 16.44 & 27.25 & 23.37 & 25.18 \\
2004 & 6.79 & 8.87 & 29.40 & 30.42 & 24.53 \\
2005 & 15.58 & 14.99 & 30.71 & 23.00 & 15.72 \\
2006 & 6.40 & 13.95 & 34.41 & 25.96 & 19.28 \\
2007 & 12.26 & 16.53 & 31.02 & 22.43 & 17.76 \\
2008 & 2.36 & 6.95 & 27.70 & 31.19 & 31.80 \\
2009 & 30.57 & 26.39 & 27.31 & 10.91 & 4.83 \\
2010 & 17.33 & 21.48 & 30.81 & 18.08 & 12.30 \\
Average & 13.51 & 16.50 & 29.73 & 22.37 & 17.90 \\
\hline
\end{tabular}

side, showed an increasing overall trend, reaching the maximum value of $28.84 \%$ in 2009 , and the minimum value of $7.01 \%$ in 2003 .

The overall grassland growth in the project area in the later period of grassland growth peak season from 2001 to 2010 was far better than that in the base year. The areas of grasslands with good, relatively good, normal, relatively poor and poor growth respectively accounted for $17.90 \%, 22.37 \%, 29.73 \%, 16.50 \%$ and $13.51 \%$ of the total grassland area in the project area (Table 2). The area of grasslands, of which the growth was on the good side, was $40.27 \%$; while that of grasslands, of which the growth was on the poor side, was $30.01 \%$. The area proportion of the grasslands, of which the growth was on the good side, fluctuated and decreased in general, while that of the grasslands, of which the growth was on the poor side, showed an increasing overall trend. The grassland growth was on the poor side in 2001 and on the good side from 2002 to 2008 , reaching the maximum value of $62.99 \%$ in 2008 . The grassland growth was on the poor side from 2009 to 2010, and the area proportions were $56.95 \%$ and $38.81 \%$, respectively.

The preceding analysis shows that the maximum growth peak season of the Beijing-Tianjin sandstorm source control area was in the first ten days of August, when the grassland growth was better than that in the last 10-day of August. The grassland growth was better in the early and later periods of the grassland growth peak season than in the year 2000 , indicating that the implementation of the Beijing-Tianjin sandstorm source control project has apparently improved the grassland vegetation growth.

\subsection{Annual dynamic variation of growth in different regions}

From the regional perceptive on four zones (Table 3), except that the grassland growth in the farming-pastoral area of desertified land control zone was on the poor side, the average growth of other three zones was on the good side. The area proportion of the grasslands, of which the growth was on the good side in northern arid grassland desertification control zone was $32.18 \%$, and that is $3.88 \%$ higher than that of the grasslands, of which the growth was on the poor side. The area proportion of the grasslands, of which the growth was on the good side in Hunshandake sandy land control zone was $34.68 \%$, boasting the biggest area proportion in the preceding four zones. The area proportion of the grasslands with normal growth in the water conservation zone of Yanshan hills and mountains was $62.64 \%$; and that of the grasslands, of which the growth was on the good side was $22.44 \%$, and that is $6.52 \%$ higher than that of the grasslands, of which the growth was on the poor side.

The average growth of the four zones was on the good side in the early and later periods of the grassland growth peak season. The area proportion of the grasslands, of which the growth was on the good side in northern arid grassland desertification control 
Table 3

Comparative growth conditions of grassland vegetation in four major zones between the base year and each year from 2001 to 2010 .

\begin{tabular}{|c|c|c|c|c|c|}
\hline \multirow[t]{2}{*}{ Regions } & \multicolumn{5}{|c|}{ Percentage of grassland area (\%) } \\
\hline & Poor & Relatively poor & Normal & Relatively good & Good \\
\hline Hunshandake sandy land control zone & 5.96 & 19.66 & 39.69 & 26.65 & 8.03 \\
\hline Water conservation zone of Yanshan hills and mountains & 1.91 & 14.01 & 61.64 & 19.82 & 2.62 \\
\hline Farming-pastoral area of desertified land control zone & 6.41 & 24.01 & 46.36 & 21.29 & 1.94 \\
\hline Northern arid grassland desertification control zone & 5.31 & 22.99 & 39.53 & 24.74 & 7.43 \\
\hline
\end{tabular}

zone, was $60.67 \%$ in the early period and $39.11 \%$ in the later period, decrease $21.56 \%$ comparatively. The area proportions of the grasslands, of which the growth was on the good side in northern arid grassland desertification control zone, were $66.36 \%$ and $46.41 \%$ in the early and later periods respectively, showing that the area proportion in the early period was higher than that in the later period. The area proportions of the grasslands, of which the growth was on the good side in the water conservation zone of Yanshan hills and mountains, were $51.64 \%$ and $23.59 \%$ in the early and later periods respectively, a gap of $28.05 \%$. The area proportions of the grasslands, of which the growth was on the good side in the farming-pastoral area of desertified land control zone, approximately were $33.82 \%$ and $37.08 \%$ in the early and later periods respectively.

\subsection{Space pattern of grassland growth}

According to the comparison between the base year and each year from 2001 to 2010 (Fig. 3), the regions with big grassland growth changes were concentrated in the western and eastern sections of the northern arid grassland desertification control zone and the western section of Hunshandake sandy land control zone. The grassland growth changes in the water conservation zone of Yanshan hills and mountains and the farming-pastoral area of desertified land control zone were relatively stable.

As to the space pattern of grassland growth in different years (Fig. 4), the regions, where the grassland growth was on the poor side, were principally concentrated in the western and southern sections of the project area; while the regions where the grassland growth was on the good side, were principally concentrated in the northeast of the project area. The grassland growth got better in the northern arid grassland desertification control zone in the west of the project area in 2002, and the area of the grasslands, of which the growth was on the poor side, declined. The grassland growth apparently got better in the middle, northern and northwestern sections of the project area in 2003. However, the regions where the grassland growth was on the poor side were distributed in the northeast of arid region in the north of the project area. The grassland growth got worse in the northern arid grassland desertification control zone in the north of the project area in 2004. The grassland growth got worse in the western region of northern arid grassland desertification control zone in the northwest of the project area, as well as the western region of Hunshandake sandy land control zone in 2005. The grassland growth got worse in the northern arid grassland desertification control zone of the north east of the project area and the Hunshandake sandy land control zone of the southeast of the area in 2006. The grassland growth got better in the water conservation zone of Yanshan hills and mountains in the south of the project area in 2007. The grassland growth got better in 2008 in the northern arid grassland desertification control zone in the northeast of the project area, while the regions, where the grassland growth got worse, in the west of northern arid grassland desertification control zone and the middle-west of Hunshandake sandy land control zone decreased. The grassland growth got worse in the east of northern arid grassland desertification control zone, the west of Hunshandake sandy land control zone and the north of the farming-pastoral area of desertified land control zone in 2009. The grassland growth got better in the northern arid grassland desertification control zone and the east of Hunshandake sandy land control zone in 2010.

\section{Discussion}

The study performs monitoring and analysis of grassland vegetation in the growing season and growth peak season in the Beijing-Tianjin sandstorm source project area. Many factors have influence on the accuracy of results in the calculation and evaluation processes by the growth index remote sensing monitoring model.

The data source of the study is MODIS data, while the essence of sensor information determines the uncertainty in the acquisition, processing and parsing process. The remote-sensing information is the plane information of ground object, which is three-dimensional, so the remote sensing data has no meaning to accurately reflect all information in the ground object. Meanwhile, there are information attenuation and mutual interference in the acquisition of remote-sensing information. The errors caused by atmosphere, sensor and terrain may be eliminated partially in the remote sensing data processing procedure. The software and man-made errors, however, may be happened in the processing procedure so that the uncertainty of remote sensing data becomes more diversified and the data fails to give an accurate evaluation.

The data building the growth index model in the study is MODIS NDVI. The vegetation index data may be influenced to a certain degree, by the components of ground surface, as well as other factors, such as internal structure of vegetation, leaves structure of vegetation, so that the data fails to completely show the accurate information of ground vegetation. The influence by the ground could be eliminated by further processing of vegetation indices after the reduction and calculation of the anomaly growth monitoring method so that the finally obtained grassland vegetation growth indices can accurately reflect the vegetation growth information.

The study uses NDVI data to build growth index model in the four zones. The underlying surfaces of different grassland types differ greatly, such as desert steppe and meadow steppe. The use of same vegetation index in different zones could preferably reflect the vegetation growth status, so the growth models of different vegetation indices may be used in different zones. In addition, the establishment of growth ground model could be further refined to increase ground sampling indices and model factors so as to obtain precise ground growth models and preferably reflect grassland vegetation growth variation.

The desertification and its damages have become major ecological environment problems in the north of China for the recent over 50 years. They not only lead to big changes of vegetation, soil, climate and moisture in the region, but also result in variations in landscape structure, function and biological and ecological processes in the desertified regions. The soaring area of desertified land has directly influenced the sustainable the social and economic development in the local region and thus threatened the ecological safety of Beijing and Tianjin economic circle. Compared with the conditions prior to the implementation of Beijing-Tianjin sandstorm source project, the growing season and growth status 

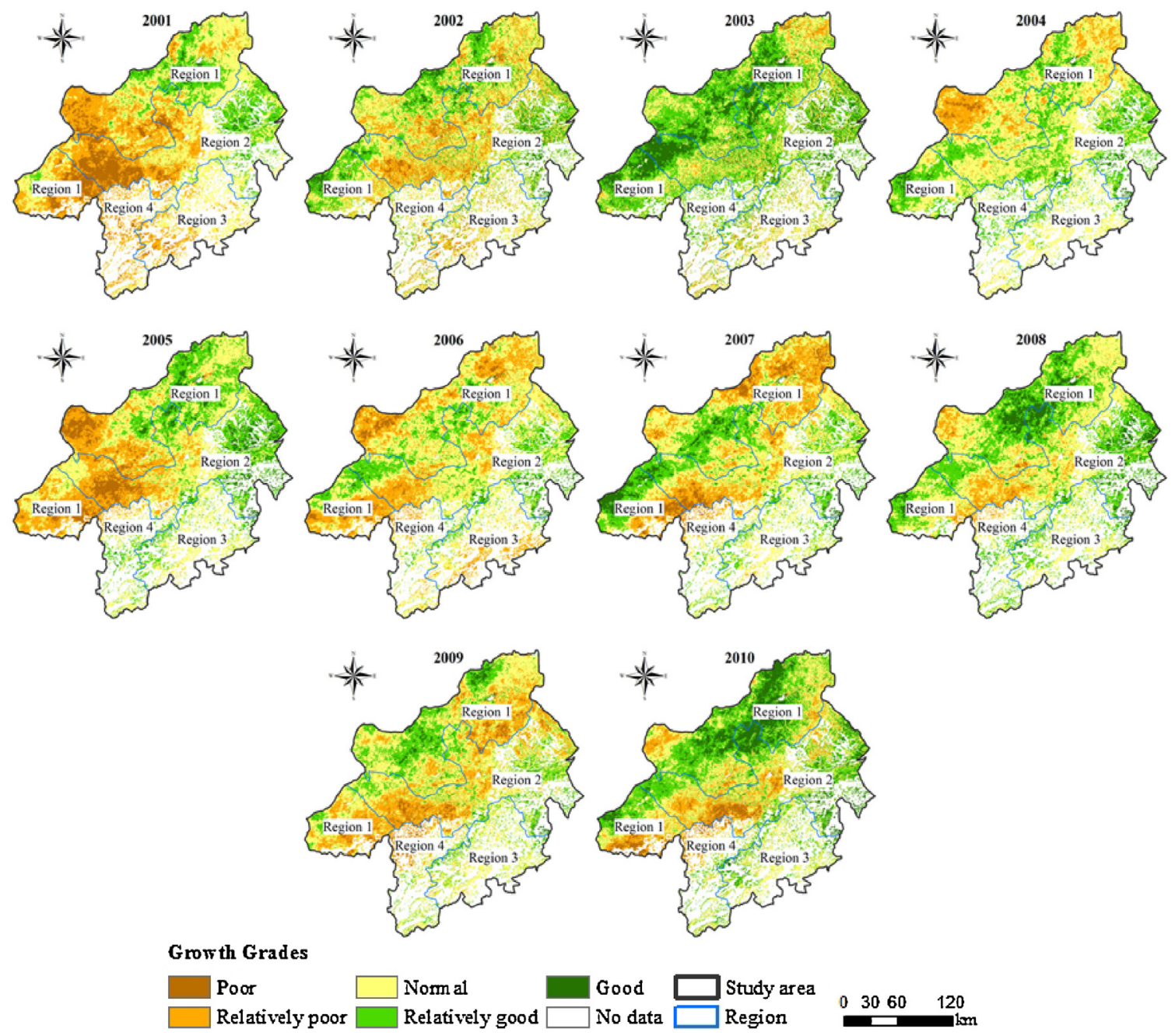

Fig. 4. Comparative spatial distribution of grassland growth between the year 2000 and each year from 2001 to 2010.

of steppe vegetation in the project area have changed for the better from 2001 to 2010, indicating that the effect of desertification control is evident to the development of sandstorm source project. As to the four zones, the steppe growth conditions in northern arid steppe desertification control zone, Hunshandake sandy land control zone and water conservation zone of Yanshan hills and mountains have been improved, while Hunshandake sandy land control zone boasts the most visible improvements in the vegetation conditions among the four zones. The ecological environment has been improved obviously after the control of more than 10 years in the Beijing-Tianjin sandstorm source project area, but there are deteriorative phenomenons, such as in the farming-pastoral area of desertified land control zone. Therefore, the sustained implementation of the project could be performed on the basis of original achievements to improve the ecologically deteriored regions, preserve the ecological safety and sustainable economic development of Beijing and Tianjin, or even North China, and thus promote the harmony between human beings and the nature.

\section{Conclusion}

The study has taken the grasslands in the Beijing-Tianjin sandstorm source project area as the research object, based on MODIS NDVI data from 2000 to 2010 and built the grassland growth index model and playbacks the grassland vegetation growth in the recent 11 years. Moreover, it conducts an analysis of grassland growth in the Beijing-Tianjin sandstorm source project area in different periods and zones on the basis of growth classification so as to obtain the following principal conclusions.

(1) The comparative results of average growth between the base year and each year from 2001 to 2010 were on the good side on the whole. The areas of the grasslands with good, relatively good, normal, relatively poor and poor growth respectively accounted for $6.92 \%, 24.80 \%, 41.92 \%, 21.05 \%$ and $5.31 \%$ of the total grassland area in the project area, indicating that the grassland growth in the project area has been improved after the project was implemented.

(2) As to the yearly dynamic variation of grassland growth, the area proportions of the grasslands, of which the average grassland growth was on the good side, fluctuated and increased slightly with the time changes in general. The area proportions of the grasslands, of which the average grassland growth was on the poor side, fluctuated and decreased in general. The area proportions of the grasslands with normal growth rose in general.

(3) The maximum growth peak season of the Beijing-Tianjin sandstorm source control zone was in the first ten days of August, when the grassland growth was far better than that in the last 10-day of August. The grassland growth was better in the early and later periods of the grassland growth peak season than in the year 2000, indicating that the implementation of the Beijing-Tianjin sandstorm source 
control project has apparently improved the growth status of grassland vegetation.

(4) From the regional perceptive on four zones, except that the grassland growth in the farming-pastoral area of desertified land control zone was on the poor side, the average growth of other three zones was on the good side.

(5) According to the comparison between the base year and each year from 2001 to 2010, the regions with big grassland growth changes were concentrated in the western and eastern sections of the northern arid grassland desertification control zone and the western section of Hunshandake sandy land control zone. The grassland growth changes in the water conservation zone of Yanshan hills and mountains and the farmingpastoral area of desertified land control zone were relatively stable.

\section{Acknowledgements}

This study was supported by the National Natural Science Foundation of China (31372354), International Science \& Technology Cooperation Program of China (2013DFR30760), Doctorial Fund Project of Xinjiang Production and Construction Corps (2012BB001), Project of Scientific and Technological Support to Xinjiang of Xinjiang Production and Construction Corps (2013AB017). We wish to acknowledge the assistance of the Department of Development and Planning and the Grassland Monitoring and Supervision Center, Ministry of Agriculture, PRC.

\section{References}

Adel, S., et al., 2007. Remote sensing and GIS for mapping and monitoring land cover and land-use changes in the Northwestern coastal zone of Egypt. Appl. Geogr. 27 (1), 28-41.

Barbosa, H.A., et al., 2006. A 20-year study of NDVI variability over the Northeast Region of Brazil. J. Arid Environ. (67), 288-307.

Beatriz, M., et al., 2009. Vegetation dynamics from NDVI time series analysis using the wavelet transform. Rem. Sens. Environ. 113 (5), 1823-1842.

Benjamin, B., et al., 2012. Mapping ecosystem service supply, demand and budgets Ecol. Indicat. 21, 17-29.

Lobell, D.B., et al., 2003. Remote sensing of regional crop production in the Yaqui Valley, Mexico: estimates and uncertainties. Agr. Ecosyst. Environ. 94 (2), 205-220.

Gonzalo, F., et al., 2010. A methodology to identify sustainability indicators in construction project management - application to infrastructure projects in Spain. Ecol. Indicat. 10 (6), 1193-1201.

Guo, J.M., et al., 2012. Simulation of regional winter wheat growth by using remote sensing data and crop model. In: SPIE Proceedings. 8513, Remote Sensing and Modeling of Ecosystems for Sustainability IX, p. 85130E, http://dx.doi.org/ 10.1117/12.930387.

Harini, N., et al., 2013. Remote sensing for conservation monitoring: assessing protected areas, habitat extent, habitat condition, species diversity, and threats. Ecol. Indicat. 33, 45-59.

Holben, B.N., 1986. Characteristics of maximum-value composite images from temporal AVHRR data. Int. J. Rem. Sens. 7 (11), 1417-1434.

Jiang, Y.B., et al., 2014. Satellite-derived vegetation indices contribute significantly to the prediction of epiphyllous liverworts. Ecol. Indicat. 38, 72-80.

John, A.G., et al., 2013. Spatial and temporal variation in primary productivity (NDVI) of coastal Alaskan tundra: decreased vegetation growth following earlier snowmelt. Rem. Sens. Environ. 129, 144-153.

Karin, S.F., et al., 1997. Estimating the Leaf Area Index of north central Wisconsin forests using Landsat thematic mapper. Rem. Sens. Environ. 61 (2), 229-245.

Mao, K.B., et al., 2012. The monitoring analysis for the drought in China by using an improved MPI method. J. Integr. Agr. 11 (6), 1048-1058.

Li, J.L., et al., 2011. Study on the seasonal dynamics of zonal vegetation of NDVI/EVI of costal zonal vegetation based on MODIS data: a case study of Spartina alterniflora salt marsh on Jiangsu Coast, China. Afr. J. Agr. Res. 6 (17), 4019-4024.

Li, W., et al., 2012. Local climate determines the NDVI-based primary productivity and flooding creates heterogeneity in semi-arid floodplain ecosystem. Ecol. Model. 242, 116-126.

Ma, Y.P., et al., 2008. Monitoring winter wheat growth in North China by combining a crop model and remote sensing data. Int. J. Appl. Earth Obs. Geoinformation 10 (4), 426-437.

Liu, M.C., et al., 2014. The calculation of productivity factor for ecological footprints in China: a methodological note. Ecol. Indicat. 38, 124-129.

Pettorelli, N., et al., 2005. Using the satellite-derived NDVI to assess ecological responses to environmental change. Trends Ecol. Evol. 20 (9), 503-510.

Pielke, A.R., et al., 1998. Interactions between the atmosphere and terrestrial ecosystems: influence on weather and climate. Globe Change Biol. 4 (5), 461-475.

Pieter, S.A.B., et al., 2006. Improved monitoring of vegetation dynamics at very high latitudes: a new method using MODIS NDVI. Rem. Sens. Environ. 100 (3), 321-334.

Tashi, Y.Z., 2004. Application research on herbage growth monitoring using NOAA satellite data in Naqu region, Tibet. Tibet Sci. Tech. 6, 35-44.

Wang, W., et al., 2006. Feedbacks of vegetation on summertime climate variability over the North American grasslands part I: statistical analysis. Earth Interact. 10 (17), 1-27.

Wittich, K., et al., 2008. The normalized difference vegetation index obtained from agro meteorological standard radiation sensors: a comparison with groundbased multiband spectroradiometer measurements during the phonological development of an oat canopy. Int. J. Biometeorol. 52 (3), 167-177.

Wu, B.F., et al., 2010. An integrated crop condition monitoring system with remote sensing. Trans. ASABE (Am. Soc. Agr. Biol. Eng.) 53 (3), 971-979.

Wu, B.F., et al., 2000. Crop growth monitor system with coupling of NOAA and VGT Data. In: Vegetation 2000 proceedings.

Xu, B., et al., 2013. MODIS-based remote-sensing monitoring of the spatiotemporal patterns of China's grassland vegetation growth. Int. J. Rem. Sens. 34 (11), 3867-3878.

Yongyut, T., et al., 2011. Plant species vulnerability to climate change in Peninsular Thailand. Appl. Geogr. 31 (3), 1106-1114.

Zhou, L., et al., 2001. Variations in northern vegetation activity inferred from satellite data of vegetation index during 1981 to 1999. J. Geophys. Res. Atmos. 106 (D17), 20069-20083. 